\title{
Períodos de InterferênCia das Plantas Daninhas na Cultura da CANA-DE-AÇÚCAR. II - CAPIM-BRAQUIÁRIA (Brachiaria decumbens) ${ }^{1}$
}

\author{
Interference Periods of Weeds in the Sugarcane Crop. II - Brachiaria decumbens
}

\begin{abstract}
KUVA, M.A. ${ }^{2}$, GRAVENA, R. ${ }^{3}$, PITELLI, R.A. ${ }^{4}$, CHRISTOFFOLETI, P.J. ${ }^{5}$ e ALVES, P.L.C.A. ${ }^{6}$
RESUMO - Um experimento foi conduzido em Olimpia-SP, com o objetivo de avaliar os efeitos de períodos de convivência e controle das plantas daninhas na produtividade da cultura da cana-de-açúcar. A cana foi plantada em maio de 1995, sendo colhida 15 meses após; a cultura anterior havia sido pastagem de Brachiaria decumbens e, em conseqüência, esta espécie foi a principal planta daninha presente na área experimental. Essa época de plantio é caracterizada por grande deficiência hídrica; mesmo assim, a população de $B$. decumbens tendeu a apresentar acúmulo crescente de biomassa seca durante todo o período de avaliação. Esse comportamento proporcionou intensa interferência na cultura da cana-de-açúcar, ocasionando $82 \%$ de redução na produtividade de colmos. A cultura pôde conviver com a comunidade infestante até 89 dias após o plantio (DAP), sem sofrer redução significativa na produtividade. O período mínimo de controle, para assegurar a máxima produtividade, foi de 138 DAP. Dessa forma, o controle das plantas daninhas foi crítico no período compreendido entre 89 e 138 DAP.
\end{abstract}

Palavras-chave: Saccharum spp., planta daninha, competição.

\begin{abstract}
A field trial was carried out in Olimpia, São Paulo, Brazil, to evaluate the effects of different periods of weed control on sugarcane yield. In the year before, the field was a Brachiaria decumbens pasture and, for this reason, this grass was the major population in the weed community. Sugarcane was planted on May 1995, at the beginning of the dry season. Despite this constraint, dry matter accumulation in B. decumbens population increased during the whole evaluated period. Thus, its interference in sugarcane plants was very strong, leading to an $82 \%$ reduction in the crop yield. Sugarcane plants could grow along with the weed community up to 89 days, without significant productivity reduction. A minimal weed control period of 138 days was required to assure maximum sugarcane productivity. The critical period for weed control was between 89 and 138 days, after planting.
\end{abstract}

Key words: Saccharum spp., weed, competition.

\section{INTRODUÇÃO}

A interferência exercida pelas plantas daninhas é um importante fator na determinação do crescimento e do desenvolvimento das culturas, sendo considerada um dos fatores mais críticos no processo produtivo da cana- de-açúcar. As perdas de produtividade decorrentes da presença de plantas daninhas são bastante variadas, podendo, em alguns casos, ser de grande expressão (Blanco et al., 1979, 1981; Rolim \& Christoffoleti, 1982; Lorenzi, 1983; Blanco et al., 1984; Keeley, 1987; Lorenzi, 1988; Coleti et al., 1997; Kuva et al., 2000).

1 Recebido para publicação em 7/8/2001 e na forma revisada em 17/12/2001.

Parte da dissertação de mestrado do primeiro autor apresentada à ESALQ/USP.

2 Eng.-Agrônomo, M.S., Monsanto do Brasil. ${ }^{3}$ Pós-graduando, M.S., Dep. de Biologia Aplicada à Agropecuária, FCAV/UNESP; ${ }^{4}$ Prof. Livre Docente, Dep. de Biologia Aplicada à Agropecuária, FCAV/UNESP. ${ }^{5}$ Prof. Doutor, Dep. de Horticultura, ESALQ/ USP. ${ }^{6}$ Prof. Assistente Doutor, Dep. de Biologia Aplicada à Agropecuária, FCAV/UNESP. 
As plantas infestantes podem interferir no processo produtivo da cana-de-açúcar através da competição por recursos do meio, principalmente água, luz e nutrientes, da liberação de substâncias alelopáticas, da atuação como hospedeiro de pragas e doenças comuns à cultura e da interferência nas práticas de colheita (Pitelli, 1985). A ocorrência de um ou mais desses componentes de interferência poderá causar reduções na quantidade da cana-deaçúcar colhida, além de diminuir o número de cortes economicamente viáveis (Lorenzi, 1988).

O grau de interferência entre as plantas cultivadas e as plantas daninhas depende de diversos fatores relacionados à comunidade infestante (composição específica, densidade e distribuição) e à própria cultura (gênero, espécie ou cultivar, espaçamento entre sulcos e densidade de semeadura). Depende também da época e duração do período de convivência e é modificado pelas condições edáficas, climáticas e pelos tratos culturais (Blanco, 1972; Pitelli, 1985).

Estudos recentes sobre períodos críticos de interferência entre plantas daninhas e a cultura da cana-de-açúcar foram realizados por Blanco et al. (1981), Rolim \& Christoffoleti (1982), Graciano \& Ramalho (1983), Blanco et al. (1984), Graciano \& Barbosa (1986), Graciano (1989), Constantin (1993), Coleti et al. (1997) e Kuva et al. (2000). As constantes mudanças no sistema de produção da canade-açúcar, com a adoção de novos espaçamentos e novas variedades, e as grandes variações nas condições de cultivo exigem a realização de estudos de períodos de interferência com maior freqüência e em diferentes locais e épocas do ano. Com a realização desses estudos, é possivel a adequação das diferentes práticas de manejo de plantas daninhas, reduzindo as perdas e o impacto ao meio ambiente provocado especialmente pelo uso inadequado de medidas de controle.

No Estado de São Paulo, é comum a expansão dos plantios de cana-de-açúcar para áreas de pastagem com capim-braquiária. O banco de sementes existente nessas áreas favorece a presença de grandes populações dessa planta daninha nos primeiros anos de cultivo, sendo necessária a adoção de práticas de controle (Constantin, 1993; Coleti et al., 1997).
O objetivo deste trabalho foi estudar os períodos críticos de interferência das plantas daninhas na produtividade da cultura de canade-açúcar plantada em área de reforma de pastagem.

\section{MATERIAL E MÉTODOS}

O experimento foi conduzido no município de Olímpia-SP, numa área de expansão do plantio da cana-de-açúcar que teve a pastagem de capim-braquiária como cultura anterior. $\mathrm{O}$ solo da área foi classificado como Podzólico arenoso e as suas principais características químicas foram: $\mathrm{pH} \mathrm{em} \mathrm{CaCl}_{2} 5,1 ; 30,2 \mathrm{~g} \mathrm{dm}^{-3}$ de matéria orgânica; $21,0^{2} \mathrm{mg} \mathrm{dm}^{-3}$ de $\mathrm{P}$; $0,58 \mathrm{mmol}_{\mathrm{c}} \mathrm{dm}^{-3} \mathrm{de} \mathrm{K} ; 4,28 \mathrm{mmol}_{\mathrm{c}} \mathrm{dm}^{-3} \mathrm{de} \mathrm{Ca}$; 1,35 $\mathrm{mmol}_{\mathrm{c}}^{\mathrm{c}} \mathrm{dm}^{-3} \mathrm{de} \mathrm{Mg} ; 4,25 \mathrm{mmol}_{\mathrm{c}} \mathrm{dm}^{-3} \mathrm{de}$ $\mathrm{H}+\mathrm{Al} ; 6,75 \mathrm{mmol}_{\mathrm{c}} \mathrm{dm}^{-3}$ de SB; $11,0 \mathrm{mmol}_{\mathrm{c}} \mathrm{dm}^{-3}$ de T; e $49 \%$ de saturação de bases. No preparo do solo, antes do plantio da cana-de-açúcar, foi realizada calagem, com incorporação de 1 t ha-1 de calcário dolomítico. A adubação foi efetuada no sulco, com $600 \mathrm{~kg} \mathrm{ha}^{-1}$ da fórmula 04-12-10 (N-P-K). A variedade de cana-de-açúcar RB835486 foi plantada no dia 30 de maio de 1995, numa densidade de 15 gemas por metro linear de sulco de plantio, com os sulcos espaçados em um metro. A colheita foi realizada 15 meses após o plantio.

Os tratamentos experimentais foram constituídos de nove períodos crescentes de convivência ou controle das plantas daninhas na cultura, considerados a partir do plantio da cana-de-açúcar. Os tratamentos foram separados em dois grupos: $\mathrm{M}$ (Mato), para os períodos iniciais de convivência com as plantas daninhas; e L (Limpo), para os períodos iniciais de controle. Os períodos de convivência ou controle avaliados foram de 0-14, 0-28, 0-49, 0-63, 0-84, 0-105, 0-126, 0-147 e 0-450 (colheita da cana) dias após o plantio da cana-deaçúcar.

Foi adotado o delineamento experimental em blocos casualizados, com quatro repetições. As parcelas experimentais foram compostas por cinco linhas de plantio de cana-de-açúcar, com 10 metros de comprimento. As avaliações foram realizadas na área útil das parcelas $\left(24 \mathrm{~m}^{2}\right)$, considerando como bordadura uma linha de plantio de cada lado da parcela e um metro de cada extremidade das três linhas centrais. 
Nas parcelas destinadas à convivência inicial da cultura com a comunidade infestante (tratamentos do grupo M), as amostragens das plantas daninhas foram realizadas ao final do período estipulado. Nessas amostragens foram utilizados quadros vazados de ferro, com $0,5 \mathrm{~m}$ de lado e $0,25 \mathrm{~m}^{2}$ de área interna, que foram lançados oito vezes, ao acaso, dentro da área útil de cada parcela. As partes aéreas das plantas encontradas nas oito amostras de cada parcela foram coletadas e separadas por espécie, determinando-se os valores médios para a densidade e para a biomassa seca de cada população. A amostragem das plantas daninhas nas parcelas destinadas aos períodos crescentes de controle da comunidade infestante (tratamentos do grupo L) foi realizada na época da colheita da cana-de-açúcar. Nesse caso, foi feita somente uma amostragem por parcela, com um quadro vazado de ferro, possuindo $1,0 \mathrm{~m}^{2}$ de área interna. As plantas que se encontravam dentro do quadro foram coletadas, determinando-se a biomassa seca total da comunidade infestante.

A cultura foi colhida no sistema de corte manual de cana queimada, e a produção foi quantificada pelo peso do total de colmos produzidos na área útil de cada parcela, utilizando um dinamômetro acoplado entre a garra hidráulica e o "braço" da carregadeira. Os dados obtidos foram extrapolados para toneladas de cana por hectare.

Os dados referentes à comunidade infestante, como densidade e biomassa seca acumulada, foram extrapolados para número de plantas e gramas de matéria seca por metro quadrado, respectivamente.

As análises dos dados de produção foram processadas separadamente dentro de cada grupo (L ou M), sendo submetidos à análise de regressão pelo modelo sigmoidal de Boltzman. Este modelo foi adaptado por Kuva et al. (2000) e obedece à equação a seguir discriminada:

$$
Y=\frac{\left(A_{1}-A_{2}\right)}{1+e^{\left(X-X_{0}\right) / d x}}+A_{2}
$$

em que $\mathrm{Y}=$ produção de cana-de-açúcar em função dos períodos de controle ou de convivência; $\mathrm{X}=$ limite superior do período de controle ou de convivência; $A_{1}=$ produção máxima obtida nas parcelas mantidas no limpo durante todo o ciclo; $\mathrm{A}_{2}$ = produção mínima obtida nas parcelas mantidas no mato durante todo o ciclo; $\left(\mathrm{A}_{1}-\mathrm{A}_{2}\right)=$ perda de produção; $\mathrm{X}_{0}=$ limite superior do período de controle ou de convivência, que corresponde ao valor intermediário entre a produção máxima e mínima; e $\mathrm{dx}=$ parâmetro que indica velocidade de perda ou ganho de produção (tg a no ponto $\mathrm{X}_{0}$ ).

Também foram realizados estudos de regressão linear entre os dados de produção e de biomassa seca acumulada pelas plantas de Brachiaria decumbens.

\section{RESULTADOS E DISCUSSÃO}

A principal espécie de planta daninha encontrada na área experimental foi Brachiaria decumbens (capim-braquiária). As demais espécies observadas durante as avaliações foram as dicotiledôneas Ipomoea spp. (cordade-viola), Sida spp. (guanxumas) e Richardia brasiliensis (poaia-branca).

O capim-braquiária foi a planta daninha da comunidade infestante que apresentou maior densidade populacional na maioria das avaliações realizadas. Inicialmente, até 63 dias de convivência, a população da comunidade infestante tendeu a ser crescente, com o capimbraquiária atingindo a densidade máxima de 169 plantas $\mathrm{m}^{-2}$ e o total de plantas infestantes de 207 plantas $\mathrm{m}^{-2}$ (Figura 1). Com o aumento dos períodos de convivência, a mortalidade das plantas foi intensificada, superando a reposição pela germinação. Aos 126 dias após o plantio foram encontradas 70 plantas $\mathrm{m}^{-2}$ de capimbraquiária, num total de 86 plantas $\mathrm{m}^{-2}$ da comunidade infestante.

Comparando os resultados obtidos para as densidades populacionais com os dados de pluviosidade determinados durante as avaliações (Figura 1), é possivel constatar que os maiores incrementos na densidade populacional do capim-braquiária e, conseqüentemente, da comunidade infestante ocorreram em resposta às precipitações ocorridas entre os 28 e 63 dias após o plantio $(25 \mathrm{~mm})$. Após esse período de chuvas, foi constatado decréscimo na densidade de plantas, provavelmente devido à redução na disponibilidade de água no solo, ocasionada pela menor quantidade de precipitações. Após os 126 dias do plantio, um novo período de precipitações favoreceu novamente o incremento populacional da comunidade infestante. 


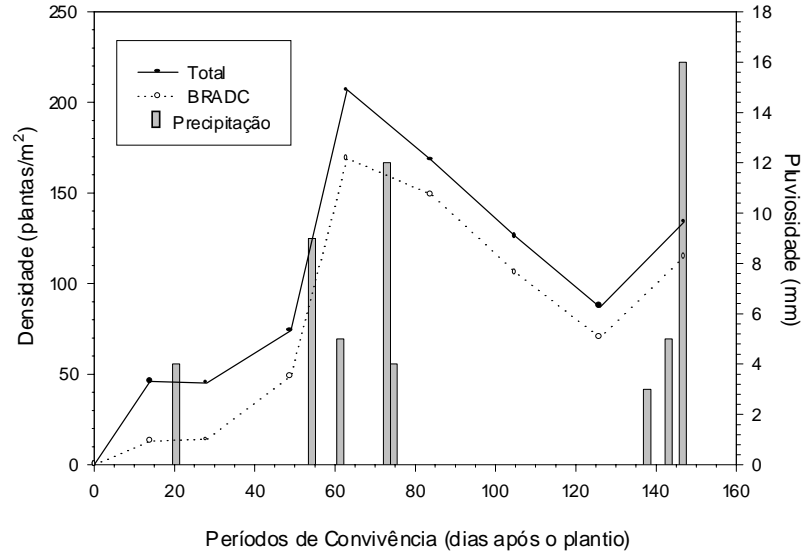

Figura 1 - Densidade da comunidade infestante e do capimbraquiária (BRADC) ao final dos períodos de convivência com a cana-de-açúcar e dados de pluviosidade observados durante os períodos. Olímpia-SP, 1995.

A exemplo do ocorrido para os resultados de densidade de indivíduos, a população de capim-braquiária foi a que apresentou maior acúmulo de biomassa seca na maioria das avaliações realizadas para a comunidade infestante. O acúmulo de biomassa seca pela comunidade infestante foi crescente durante quase todo o período de estudo (Figura 2). Somente ocorreu redução no valor de biomassa seca entre os períodos de 105 e 126 dias após o plantio, provavelmente em decorrência do período sem precipitações ocorrido entre 84 e 126 dias após o plantio (Figura 1). Posteriormente, as plantas daninhas retomaram o crescimento, resultando num grande acúmulo de biomassa seca ao final dos 147 dias de convivência $\left(240 \mathrm{~g} \mathrm{~m}^{-2}\right)$, mesmo com as restrições de água e o provável sombreamento promovido pela cana-de-açúcar. Aos 147 dias após o plantio, o capim-braquiária acumulou $171 \mathrm{~g} \mathrm{~m}^{-2}$, correspondendo a $71 \%$ do total da comunidade infestante.

Na colheita da cana-de-açúcar, a única população de planta daninha presente nos tratamentos foi a do capim-braquiária. Na Figura 3 estão apresentados os valores de biomassa seca acumulada pelo capim-braquiária, ao final do ciclo da cultura, em função dos diferentes períodos iniciais de controle. Na ausência do controle das plantas daninhas, durante todo o ciclo da cultura, o capim-braquiária acumulou cerca de $400 \mathrm{~g} \mathrm{~m}^{-2}$, por ocasião da colheita. Com o início do controle e o aumento gradativo dos períodos abrangidos por este, houve tendência de redução no acúmulo de biomassa seca pelas plantas de capim-braquiária. No entanto, independentemente da extensão dos períodos iniciais de controle, a comunidade infestante apresentou novos surtos de emergência na área experimental, com significativos acúmulos de biomassa seca na ocasião da colheita da cultura. Esse resultado evidencia uma característica importante de agressividade dessa planta daninha, que é a desuniformidade de germinação.

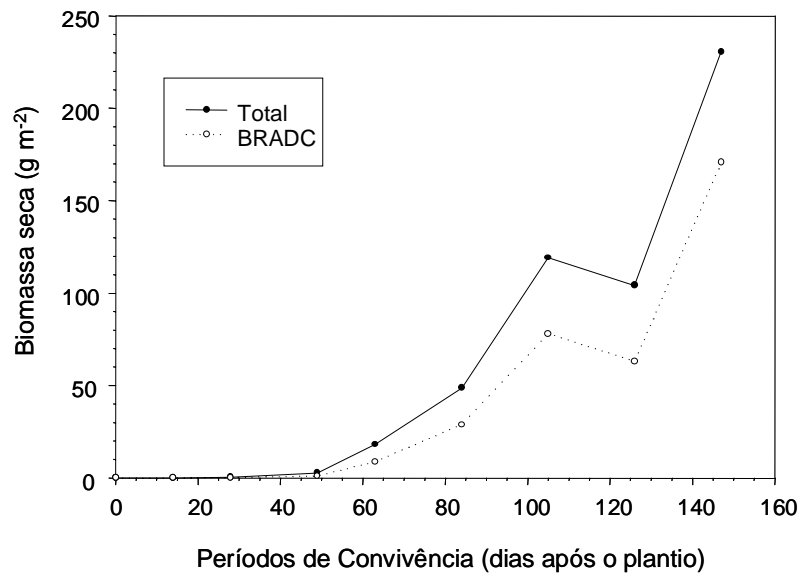

Figura 2 - Biomassa seca acumulada pela comunidade infestante e pelo capim-braquiária (BRADC) ao final dos períodos de convivência com a cana-de-açúcar. OlímpiaSP, 1995.

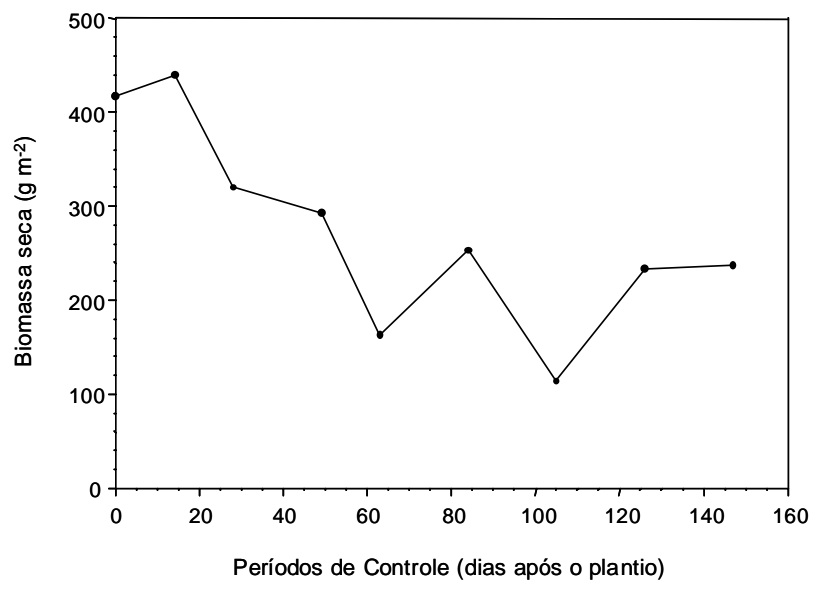

Figura 3 - Biomassa seca acumulada pela comunidade infestante (capim-braquiária, BRADC) quando submetida a diferentes períodos iniciais de controle. Olímpia-SP, 1995. 
Segundo Serrão \& Simão Neto (1971) e Seiffert (1980), o capim-braquiária é uma planta que apresenta alta resposta às adubações fosfatadas aplicadas no solo, não desenvolvendo boa quantidade de biomassa seca em solos com baixos teores de fósforo e potássio. Assim, a adubação realizada no presente experimento, com alto teor desses nutrientes, pode ter favorecido o desenvolvimento do capimbraquiária, permitindo o grande acúmulo de biomassa seca que foi observado nas avaliações da comunidade infestante.

A produtividade da cana-de-açúcar na ausência da interferência das plantas daninhas foi de $100 \mathrm{t} \mathrm{ha}^{-1}$. A convivência entre a cultura e a comunidade infestante, até a colheita, permitiu intensa interferência competitiva, resultando em $82 \%$ de redução na produtividade da cultura (Figura 4). A produtividade na presença das plantas daninhas foi de apenas $18 \mathrm{tha}^{-1}$.

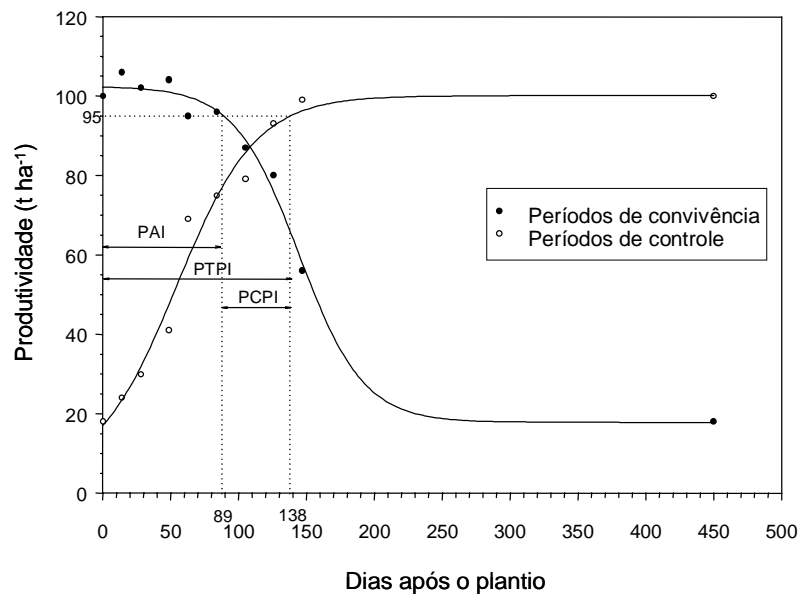

Figura 4 - Produtividade percentual de colmos de cana-deaçúcar e regressão dos dados pelo modelo sigmoidal, em função dos períodos com controle ou com convivência das plantas daninhas. Olímpia-SP, 1995. PAI - período anterior à interferência; PTPI - período total de prevenção à interferência; PCPI - período crítico de prevenção à interferência.

Rolim \& Christoffoleti (1982), estudando uma comunidade infestante com predominância de monocotiledôneas, numa área de cana plantada na época das chuvas, obtiveram resultados parecidos, ocorrendo $86,5 \%$ de redução na produtividade da cana-de-açúcar, em decorrência da interferência competitiva das plantas daninhas. Por outro lado, estudos realizados por Constantin (1993), na época das chuvas, e Coleti et al. (1997), na época da seca, em que a planta daninha predominante foi $o$ capim-braquiária, resultaram em reduções na produtividade de 37,5 e $48 \%$, respectivamente. Além de diminuir a produtividade, a presença do capim-braquiária em altas densidades pode reduzir a longevidade do canavial (Lorenzi, 1983). Segundo o mesmo autor, as reduções na produtividade ocasionadas pelas plantas daninhas em cana-de-açúcar oscilam entre 25 e $86 \%$ da produtividade esperada.

Em função da época em que foi desenvolvido o experimento, o crescimento inicial da cultura e das plantas daninhas ocorreu nos meses em que há deficiência hídrica, podendo ter havido intensa competição por água. Com o reinício das chuvas, na primavera, a cultura e a comunidade infestante aceleram o desenvolvimento, incrementando a competição por nutrientes. Estudos conduzidos em casa de vegetação indicaram que uma população de capim-braquiária de 40 plantas $\mathrm{m}^{-2}$ é capaz de acumular, aos 160 dias após a emergência, $79 \mathrm{~kg} \mathrm{ha}^{-1}$ de $\mathrm{N}$ total, $11 \mathrm{~kg} \mathrm{ha}^{-1} \mathrm{de}$ P, $166 \mathrm{~kg} \mathrm{ha}^{-1}$ de $\mathrm{K}, 63 \mathrm{~kg} \mathrm{ha}^{-1}$ de $\mathrm{Ca}, 39 \mathrm{~kg} \mathrm{ha}^{-1}$ de $\mathrm{Mg}$ e $16 \mathrm{~kg} \mathrm{ha}^{-1}$ de S (BIANCO et al., 2000).

Estudos de regressão linear mostraram que, com o aumento da biomassa seca do capimbraquiária, houve redução na produtividade de colmos pela cana-de-açúcar (Figura 5). No caso da comunidade infestante que conviveu com a cultura no início do ciclo, o acúmulo de $3,70 \mathrm{~g} \mathrm{~m}^{-2}$ pelo capim-braquiária proporcionou redução de $1 \mathrm{t} \mathrm{ha}^{-1}$ na produtividade da cultura. No entanto, em função dos períodos iniciais de controle, foi necessário acúmulo de $4,34 \mathrm{~g} \mathrm{~m}^{-2}$ pelo capim-braquiária para redução da produtividade em $1 \mathrm{t} \mathrm{ha}^{-1}$.

A representação gráfica e os parâmetros da equação sigmoidal de Boltzman obtidos para a regressão dos dados de produtividade, em função dos períodos de convivência e controle das plantas daninhas, estão apresentados na Figura 4 e na Tabela 1, respectivamente. Admitindo perda máxima de 5\% em relação à produtividade obtida na ausência total de plantas daninhas, pode-se observar que a produtividade da cana-de-açúcar passou a ser afetada negativamente a partir de 89 dias de convivência 


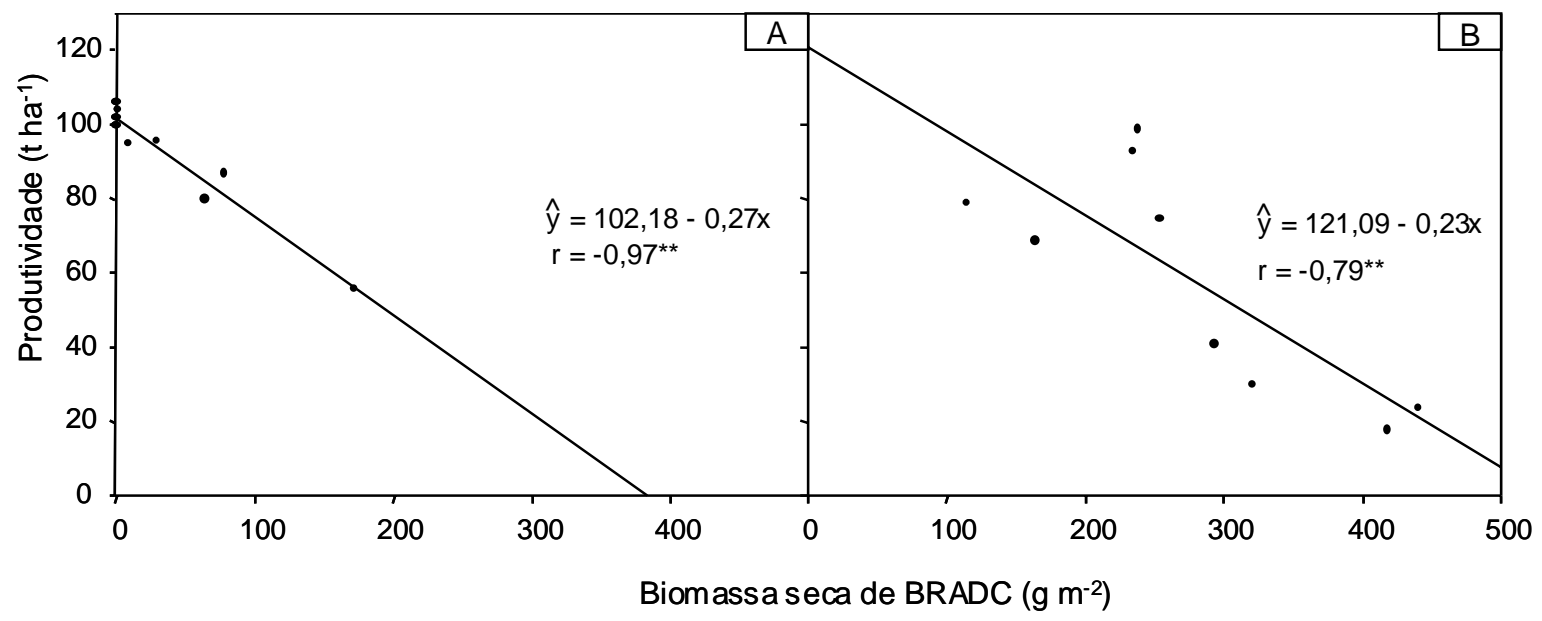

Figura 5 - Estimativa da produtividade de colmos de cana-de-açúcar, para os períodos crescentes de convivência (A) e controle (B), em função da biomassa seca acumulada pelo capim-braquiária (BRADC). Olímpia-SP, 1995.

(Período Anterior à Interferência - PAI) (Figura 4). Por outro lado, foi necessário o controle da comunidade infestante por 138 dias para que a produção atingisse $95 \%$ da produtividade máxima (Período Total de Prevenção à Interferência - PTPI) (Figura 4). Assim, o controle das plantas daninhas foi crítico no período compreendido entre 89 e 138 DAP (Período Crítico de Prevenção à Interferência - PCPI) (Figura 4).

Tabela 1 - Parâmetros da equação sigmoidal, obtidos da análise de regressão dos dados de produtividade de cana-de-açúcar. Olímpia-SP, 1995

\begin{tabular}{|c|c|r|}
\hline Parâmetros & Convivência & Controle \\
\hline $\mathrm{A}_{1}$ & 102,43 & 4,13 \\
$\mathrm{~A}_{2}$ & 17,79 & 100,10 \\
$\mathrm{x}_{0}$ & 144,64 & 54,42 \\
$\mathrm{dx}$ & 23,73 & 29,16 \\
\hline $\mathrm{r}^{2}$ & 0,989 & 0,978 \\
\hline
\end{tabular}

Coleti et al. (1997), também na região de Olímpia-SP e na mesma época de plantio, determinaram que o controle do capim-braquiária foi necessário dos 60 aos $81 \mathrm{DAP}$, para garantir a produtividade da cana-de-açúcar. Concluíram, ainda, que o capim-braquiária possui alta capacidade de reinfestação, principalmente durante o período crítico de desenvolvimento da cana-de-açúcar. Todavia, se o controle for bem feito nesse período, as reinfestações posteriores não chegam a causar prejuízos à produtividade.

Constantin (1993), também em condições de infestação com capim-braquiária, obteve resultados bem diferentes. No entanto, o plantio desse experimento foi realizado na época das chuvas, sendo "cana de ano". A produtividade da cana-de-açúcar passou a ser afetada negativamente a partir de 70 dias de convivência e foram necessários somente 49 dias de controle da comunidade infestante para que não houvesse redução significativa na produtividade. Esse autor concluiu que uma única operação de controle das plantas daninhas poderia permitir à cultura expressar plenamente seu potencial produtivo, desde que realizada entre 49 e 70 dias após o plantio. Ressaltou que esse curto período de controle ocorreu em função da época e do local em que foi instalado o experimento (outubro), do espaçamento entre as linhas de plantio $(1,10 \mathrm{~m})$ e da variedade utilizada, permitindo rápido crescimento e sombreamento das entrelinhas. Outro fator importante foi o padrão de germinação das sementes do capim-braquiária, que ocorreu concentrada nos primeiros 35 dias.

A Tabela 2 apresenta a estimativa dos valores do limite superior do período anterior à interferência (PAI) e do período total de prevenção à interferência (PTPI) em função da 
tolerância de redução de 2,5 e $10 \%$ na produtividade da cana-de-açúcar. Tolerando $10 \%$ de redução na produtividade, o PAI foi de zero aos 103 DAP e o PTPI foi de zero aos 117 DAP. Reduzindo os níveis de tolerância para $2 \%$, o PAI passou para 76 dias e o PTPI para 165 dias. Para que a redução na produtividade da canade-açúcar passasse de 2 para 10\%, foi necessário acréscimo de 27 dias no período de convivência. Por outro lado, para aumentar a produtividade de 90 para $98 \%$, foi necessário acréscimo de 48 dias no período de controle (Tabela 2).

Tabela 2 - Variação do período anterior à interferência e do período total de prevenção à interferência em função das porcentagens de redução de produtividade toleradas. Olímpia-SP, 1995

\begin{tabular}{|l|c|c|c|c|}
\hline \multirow{2}{*}{\multicolumn{1}{|c|}{ Períodos }} & \multicolumn{5}{c|}{ Porcentagens de redução } \\
\cline { 2 - 5 } & $2 \%$ & $5 \%$ & $10 \%$ & $2-10 \%$ \\
\hline $\begin{array}{l}\text { Período anterior à } \\
\text { interferência (PAI) }\end{array}$ & $0-76$ & $0-89$ & $0-103$ & 27 dias \\
\hline $\begin{array}{l}\text { Período total de prevenção } \\
\text { à interferência (PTPI) }\end{array}$ & $0-165$ & $0-138$ & $0-117$ & 48 dias \\
\hline
\end{tabular}

Nas situações em que o período crítico de prevenção à interferência (PCPI) é muito longo, a principal medida de controle para minimizar as perdas de produtividade é a utilização de produtos químicos aplicados em área total, pois o controle pela utilização de capinas manuais ou equipamentos mecânicos exigiria elevada freqüência de operações, resultando em aumento nos custos de produção. A aplicação dos herbicidas poderia ser feita logo após o plantio, utilizando tratamentos (formulações comerciais isoladas ou em misturas) com extenso período residual de controle, suficiente para suprimir as plantas daninhas durante todo o PTPI, sendo aplicado em pré-emergência ou pós-emergência das plantas daninhas em estágios iniciais de desenvolvimento. Outra opção é a aplicação de tratamentos ao final do PAI, com controle residual igual ou superior ao PCPI. Nesse caso, devem ser utilizados tratamentos com eficiência sobre as plantas daninhas em estágios mais avançados de desenvolvimento.

\section{LITERATURA CITADA}

BIANCO, S.; TONHÃO, M.A.R.; ALVES, P.L.C.A.; BRENDOLAN, R.A. Produção de matéria seca e marcha de absorção de macronutrientes por plantas de capim-braquiária. In: CONGRESSO BRASILEIRO DA CIENCIA DAS PLANTAS DANINHAS, 22, 2000, Foz do Iguaçu. Anais... Foz do Iguaçu: SBCPD, 2000. p.61.

BLANCO, H.G. A importância dos estudos ecológicos nos programas de controle de plantas daninhas. Biológico, v.38, n.10, p.343-350, 1972 .

BLANCO, H.G.; OLIVEIRA, D.A.; ARAÚJO, J.B.M. Competição entre plantas daninhas e a cultura da cana-de-açúcar. I - Período crítico de competição produzido por uma comunidade natural de dicotiledôneas em cultura de ano. Biológico, v.45, n.7/8, p.131-140, 1979.

BLANCO, H.G.; OLIVEIRA, D.A.; COLETI, J.T. Competição entre plantas daninhas e a cultura da cana-de-açúcar. II - Período de competição produzido por uma comunidade natural de mato, com predominio de gramíneas, em cultura de ano. III - Influência da competição na nutrição da cana-de-açúcar. Biológico, v.47, n.3, p.77-88, 1981.

BLANCO, H.G.; BARBOSA, J.C.; OLIVEIRA, D.A. Competição entre plantas daninhas e a cultura da cana-de-açúcar (Saccharum sp.). IV - Período de competição produzido por uma comunidade natural de mato em cultura de ano e meio. Biológico, v.50, n.10, p.237-245, 1984.

COLETI, J.T.; CAVALCANTI JR., N.; NEME, L.H.; DE PAULA, J.; ALBINO, F.E. Brachiaria pode provocar sérios danos nos canaviais. Inf. Coopercitrus, n.132, p.34-35, 1997.

CONSTANTIN, J. Efeitos de diferentes períodos de controle e convivência da Brachiaria decumbens Stapf. com a cana-de-açúcar (Saccharum spp.). Botucatu, UNESP, 1993. 98p. Dissertação (Mestrado em Agronomia) Universidade Estadual Paulista, 1993.

GRACIANO, P.A. Interferência e manejo de plantas daninhas em áreas de cana-de-açúcar (Saccharum spp.) intercalada com feijões (Phaseolus vulgaris e Vigna unguiculata L. Walp.). Piracicaba: ESALQ, 1989. 184p. Dissertação (Mestrado em Fitotecnia) - Escola Superior de Agricultura “Luiz de Queiroz”, 1989. 
GRACIANO, P.A.; RAMALHO, J.F.G.P. Efeito da matocompetição na cultura da cana-de-açúcar. STAB, v.1, n.5, p.22-24, 1983.

GRACIANO, P.A.; BARBOSA, G.V.S. Efeitos da matocompetição sobre a cultura da cana-deaçúcar - variedade Co 997. In: CONGRESSO BRASILEIRO DE HERBICIDAS E PLANTAS DANINHAS, 16, 1986, Campo Grande. Anais... Campo Grande: SBHDE, 1986. p.16.

KEELEY, P.E. Interference and interaction of purple and yellow nutsedges (Cyperus rotundus and C. esculentus) with crops. Weed Technol., v.1, n. 1, p.74-81, 1987.

KUVA, M.A.; PITELLI, R.A.; CHRISTOFFOLETI, P.J.; ALVES, P.L.C.A. Períodos de interferência das plantas daninhas na cultura da cana-de-açúcar. I - Tiririca. Planta Daninha, v.18, n.2, p.241$251,2000$.

LORENZI, H. Plantas daninhas e seu controle na cultura da cana-de-açúcar. In: REUNIÃO TÉCNICA AGRONÔMICA COOPERSUCAR: PRAGAS DA CULTURA DA CANA-DE-AÇÚCAR, 1983, Piracicaba. Anais... São Paulo: COOPERSUCAR, 1983. p.59-73.
LORENZI, H. Plantas daninhas e seu controle na cultura da cana-de-açúcar. In: SEMINÁRIO DE TECNOLOGIA AGRONÔMICA, 4, 1988, Piracicaba. Anais... São Paulo: COOPERSUCAR, 1988. p.281-301.

PITELLI, R.A. Interferência de plantas daninhas em culturas agrícolas. Inf. Agropec., v.11, n.129, p.16-27, 1985.

ROLIM, J.C.; CHRISTOFFOLETI, P.J. Período crítico de competição de plantas daninhas com cana planta de ano. Saccharum APC, v.5, n.22, p.21$26,1982$.

SEIFFERT, N.F. Gramíneas forragei ras do gênero Brachiaria. Campo Grande: EMBRAPA/Centro Nacional de Pesquisa do Gado de Corte, 1980. 83p. (Circular Técnica, 1).

SERRÃO, E.A.A.; SIMÃO NETO, M.S. Informações sobre duas espécies de gramíneas forrageiras do gênero Brachiaria na Amazônia: $B$. decumbens Stapf. e B. ruziziensis Germain et Everard. Belém: IPEAN, 1971. 31p. (Série Estudos sobre Forrageiras na Amazônia, 1) 